\title{
Acute Appendicitis with Pyogenic Liver Abscesses
}

\author{
Matteo Giardini*, Stefan Breitenstein, Felix Grieder and Lukas Gantner \\ Department of Surgery, Cantonal Hospital of Winterthur, Switzerland
}

*Corresponding author: Matteo Giardini, Department of Surgery, Cantonal Hospital of Winterthur, Winterthur, Switzerland

\section{ARTICLE INFO}

Received: 彗 January 19, 2022

Published: 幽 January 25, 2022

Citation: Matteo Giardini, Stefan Breitenstein, Felix Grieder and Lukas Gantner. Acute Appendicitis with Pyogenic Liver Abscesses. Biomed J Sci \& Tech Res 41(2)2022. BJSTR. MS.ID.006577.

\section{ABSTRACT}

Objective: Acute appendicitis, although very common and well known, can present in many different ways, from asymptomatic to septic shock and every variation in between. We offer a safe management of pyogenic liver abscesses caused by acute appendicitis.

Design: We present the case of a male patient with liver abscesses due to acute appendicitis.

Results: Liver abscesses require a multidisciplinary approach and surgical as well as interventional treatment must be evaluated in addition to an antibiotic regimen.

Conclusions: The minimally invasive management of liver abscesses with antibiotics and drainage has shown to be effective with minimal risk to the patient.

\section{Summary}

Acute appendicitis is one of the most common surgical pathologies globally and its treatment has been well practiced for many years. However, clinically it can present in many different ways, from asymptomatic to septic shock and every variation in between. We present the case of a middle-aged man presenting with fever as his only symptom. Upon clinical examination, blood evaluation and imaging, an acute appendicitis with multiple pyogenic liver abscesses were found. The patient underwent surgery with removal of the appendix and drainage of the abscesses. With an antibiotic regiment over several weeks and drainage placement the abscesses could be drained successfully, and the patient remained asymptomatic during the follow-up over 6 weeks.

\section{Background}

Acute appendicitis is a very common surgical emergency. The laparoscopic removal is the standard of care all around the world. Despite the discussion of conservative treatment of acute appendicitis with antibiotics, the American College of Surgeons, the European Association of Endoscopic Surgery and the World Society of Emergency Surgery all recommend the treatment by appendectomy $[1,2]$. In an international collaboration, researchers found that $95.7 \%$ of patients with acute appendicitis were treated operatively [1]. The lifetime risk of acute appendicitis is 8.6 percent in males and 6.9 in females [3] and the mortality in developed countries lies between 0.09 and 0.24 percent [4]. Typical complications include the perforation of the appendix (observed in $13-20 \%$ of acute appendicitis cases), which can result in peritonitis [5]. More rarely, a perityphlitic abscess can form in the proximity of the appendix. The hematogenic spread of bacteria due to an acute appendicitis is possible and has been described. This can lead to the formation of abscesses in the liver through pyemia of the portal vein [6].

Liver abscesses are relatively rare and present 2.3 cases per 100,000 people [7-9], but they account for 48 percent of visceral 
abscesses and $13 \%$ of intraabdominal abscesses [10]. In half of the cases, an underlying disease of the biliary tract can be identified, and the abscesses are often formed following a pyemia of the portal vein due to bowel leakage and peritonitis $[6,7,11]$. The most common pathogens are Streptococci, especially the Streptococcus milleri group (S. anginosus, S. constellatus, S. intermedius) [12]. Other pathogens include E. coli, K. pneumoniae and S. aureus $[13,14]$. The symptoms include fever (90\%) and unspecific abdominal complaints (50-75\%) (6-8,15). Blood work findings usually include elevated alkaline phosphatase (70-90\%), Bilirubin and liver enzymes (50\%) $[6,7,15]$.

\section{Case Presentation}

A 51-year-old male presented in our emergency department with a 4-day history of fever up to $39.0^{\circ} \mathrm{C}$. He did not complain of pain, denied any nausea or diarrhea, and had no urinary symptoms. He had no trouble breathing, no coughing and no throat pain. A Covid-19- PCR-Test was negative. He presented with normal blood pressure, tachycardia with a pulse rate of $126 / \mathrm{min}$, a body temperature of $37.7^{\circ} \mathrm{C}$, an oxygen saturation of $97 \%$ and a breathing rate of $20 \mathrm{bpm}$. The patient had no personal history of illnesses, no previous operations and did not take regular medication. A blood sample revealed a leucocyte count of $21.48 \mathrm{G} / \mathrm{l}$ with predominantly neutrophil granulocytes $(18.85 \mathrm{G} / \mathrm{l})$ and a thrombocytosis of 731 G/l. The Acute-phase proteins were significantly high with a C-reactive protein of $237 \mathrm{mg} / \mathrm{l}$, Procalcitonin of $10.48 \mathrm{ng} / \mathrm{ml}$ and Ferritin of $4593 \mu \mathrm{g} / \mathrm{l}$. He also showed elevated liver enzymes (GOT $97 \mathrm{U} / \mathrm{l}, \mathrm{GPT} 87 \mathrm{U} / \mathrm{l}$ ) and elevated cholestasis parameters (y-GT $472 \mathrm{U} / \mathrm{l}$, ALP $242 \mathrm{U} / \mathrm{l}$ and Bilirubin $47.7 \mu \mathrm{mol} / \mathrm{l}$ ) upon which we performed a sonography of the abdomen.

The ultrasound scan showed no evidence of cholecystitis or cholezystolithiasis, but multiple liver lesions, which warranted further investigation by computer tomography. The findings of the CT scan corresponded with the ultrasound images and showed multiple liver lesions and a possible appendicitis. The lesions were located in segment VI $(6.4 \times 7.2 \times 6.1 \mathrm{~cm})$ and subcapsular in the segments VII/VIII $(11.0 \times 12,1 \times 7.3 \mathrm{~cm})$ and were suggestive of liver abscesses. The working diagnosis of acute appendicitis with pyogenic liver abscesses was established. The patient was hospitalized. Blood samples with bacterial cultures, serology for parasites (amoeba, echinococcosis) and viruses (HIV, HAV, HBV, HCV) were obtained and the patient underwent surgery. The diagnostic laparoscopy showed an acute appendicitis without perifocal abscess formation. The appendix was removed at the cecal pole using a linear stapling device (Endo-GIA, $45 \mathrm{~mm}$ ).

Upon inspection and palpation of the liver perforation of the caudal abscess with purulent discharge occured. A microbiotic sample was obtained and a drainage was placed in the abscess cavity, which quickly collected $300 \mathrm{ml}$ of pus. The cranial (subdiaphragmal) liver abscess was left untouched for later interventional drainageplacement. The blood culture showed growth of Streptococcus milleri, which coincided with the findings of the intraoperative sample from the abscess. An intravenous antibiotic regiment with Metronidazol and Ceftriaxon was initiated. 7 days after drain removal the antibiotic treatment with Ceftriaxon was changed to Amoxicillin and Probenecid according to the antibiogramm results.

The histology of the appendix showed pyogenic inflammation with no signs for malignancy, further supporting the working diagnosis of acute appendicitis with hematogenous liver abscesses. The serology (viruses and parasites) results all turned out to be negative. Upon interdisciplinary discussion and according to well established treatment practice [16], the cranial abscess was drained percutaneously $(25 \mathrm{~cm}, 10$ French), which immediately released $135 \mathrm{ml}$ of pus. Further bacteriological samples were obtained, which again confirmed Streptococcus milleri. After a few days the drain was removed after complete drainage.During the hospitalization period, the patient remained afebrile and without any symptoms apart from general fatigue. The patient was discharged from hospital after 15 days with an oral antibiotic regiment containing Metronidazol, Amoxicillin and Probenecid. 
Investigation Images (Figures $1 \& 2$ )

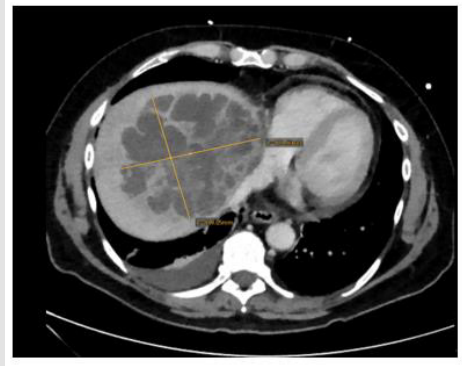

Day of admission
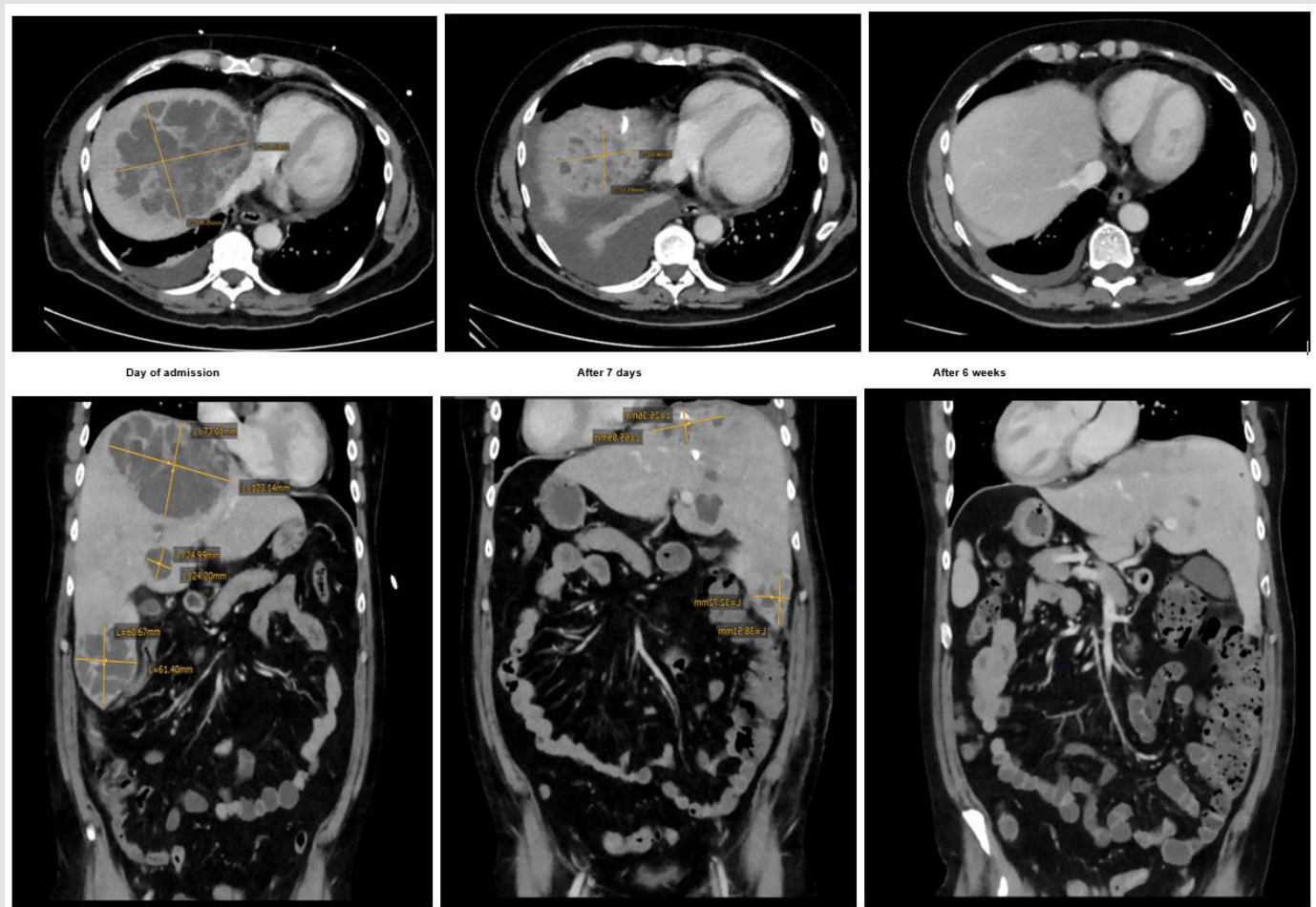

After 6 weeks

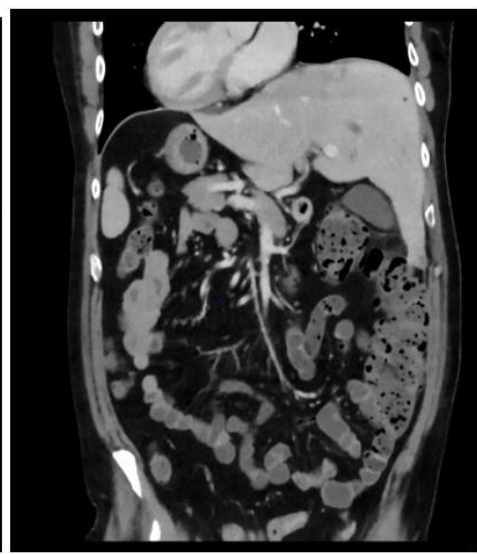

Figure 1: 6 weeks course with evident size reduction of the liver abscesses.
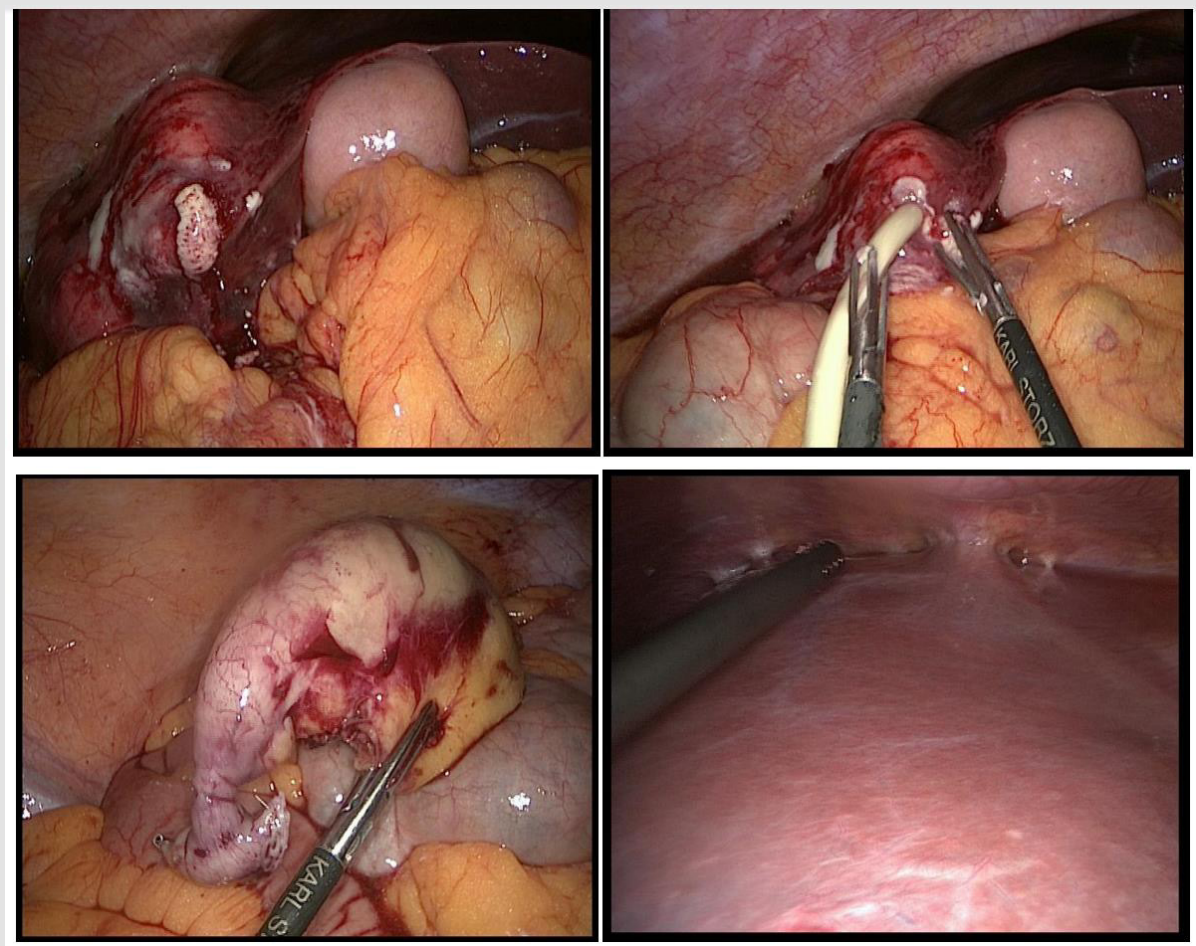

Figure 2: Intraoperative situs: Top left and right: Spontaneus perforation of the caudal liver abscess with consecutive drainage insertion. Bottom left: Appendix (stapled and resected, apex on the right, basis on the left). Bottom right: View of the subdiaphragmal abscess with adhesions 


\section{Treatment}

\section{Antibiotic Treatment}

Ceftriaxon i.v. 2g, 17.05-01.06.2020

(total duration 14d).

Metronidazol i.v. $1500 \mathrm{mg}, 17.05-20.05 .2020$

(total duration 3d).

Metronidazol p.o. 500mg, 20.05-08.07.2020

(total duration 49d).

Amoxicillin p.o. 3000mg, 20.05-08.07.2020

(total duration 49d).

Probenecid p.o. 1000mg, 20.05-08.07.2020

(total duration 49d).

\section{Surgical Treatment}

1. 17.05.2020: Laparoscopic appendectomy and drainage of liver abscess (total duration of drainage: 8 days).

2. 20.05.2020: Ultrasound-guided drainage of liver abscess (total duration of drainage: 6 days).

\section{Supportive Treatment}

1. Respiratory physiotherapy

\section{Outcome and Follow-Up}

The patient was seen weekly for follow-up examinations over the course of 6 weeks after discharge. During this period, the patient presented himself once with tachycardia and episodes of sweating in the emergency department. Computer tomography ruled out a pulmonary embolism but showed a thrombus of the medial hepatic vein. Oral anticoagulation with Rivaroxaban $20 \mathrm{mg}$ daily was established for a planned total duration of 3 months. The antibiotic treatment was continued until the abscesses could no longer be identified in the CAT scan. The patient remained afebrile and did not show any symptoms, apart from fatigue, during followup. The antibiotic treatment could be discontinued as planned, 7 weeks after initiation.

\section{Discussion}

The treatment of pyogenic liver abscesses consists of abscess drainage and antibiotic therapy [17-20]. The therapeutic approach depends on the number and size of liver abscesses. For single, unilocular abscesses smaller than $5 \mathrm{~cm}$ in diameter, a percutaneous drainage is indicated. This can either be performed through needle aspiration or catheter placement, both bearing similar success rates [17,21-23]. However, needle aspiration has to be repeated in approximately half of the cases [22-24]. In the case of a single, unilocular abscess bigger than $5 \mathrm{~cm}$ in diameter, a percutaneous drainage with a catheter placement is recommended. With needle aspiration of these larger abscesses the results show slower abscess drainage, longer time to clinical improvement and more often the need for surgical intervention compared to patients with catheter placement [17]. This management should also be applied to very large abscesses (larger than $10 \mathrm{~cm}$ in diameter), so called "giant abscesses". With a size of over $10 \mathrm{~cm}$ in diameter, the risk of complications, including drainage failure and even sepsis leading to death, become significantly higher $[8,24,25]$. There have been attempts to manage these abscesses surgically, which have shown a lower rate of treatment failure.

However, no change in mortality, duration of clinical manifestation or rate of complications could be identified in the comparison between percutaneous and surgical drainage $[26,27]$. The therapeutic approach to multiple abscesses should be made by a multidisciplinary team according to the various capabilities and experiences. The successful percutaneous drainage of multiloculated and multiple abscesses has been described [28], which led to a shift in treatment strategy from surgical to an interventional approach. The empiric antibiotic regiment with ceftriaxone and metronidazole is recommended, such that Streptococci, enteric gram-negative bacilli and anaerobes are covered. Alternative regiments should be applied according to local resistances or probable infection pattern. Antibiotic regiments should generally be continued for a total duration of 4-6 weeks, in patients with incomplete drainage the antibiotic application should be intravenously for the whole duration, whereas patients that showed a positive response to drainage can continue the antibiotic therapy orally after $2-4$ weeks of parenteral application $[21,29,30]$.

In the case of our patient, the more caudal abscess perforated spontaneously during a laparoscopy. A drainage was inserted, and microbiological samples were taken, which helped identify the responsible pathogen. According to the stated guidelines, we initiated the antibiotic treatment and inserted a percutaneous drainage of the cranial abscess, which was left untouched during surgery. Our case shows the importance of a multidisciplinary approach and shows the efficacy of surgical as well as interventional percutaneous drainage of liver abscesses.

\section{Take Home Messages}

1. Acute appendicitis is a medical chameleon: although one of the more common pathologies, it can have very diverse clinical manifestations.

2. The clinical findings and symptoms do not always correlate with the gravity of an illness.

3. Acute appendicitis, even if abdominally asymptomatic, can lead to extensive pyemia and abscess formation 
4. The minimally invasive management of liver abscesses with antibiotics and drainage has shown to be effective with minimal risk to the patient.

\section{Patient's Perspective}

The patient came in for follow-up as planned over a period of 6 weeks after discharge and was always compliant with the medical recommendations. He repeatedly stated that he could never have imagined having liver abscesses, especially considering he initially only experienced fever as main symptom. He stated that he was more worried about the drains than about the surgeries.

\section{Acknowledgement}

We would like to acknowledge Dr. med. Felix Grieder as he was the primary surgeon in charge of treatment decisions in this case. Additionally, we want to acknowledge Prof. Dr. med. Stefan Breitenstein, PD Dr. med. Filip Grochola and Dr. med. Georgios Peros and thank them for helpful discussions.

\section{Conflict of Interest}

No conflict of interest with any institution/organization.

\section{References}

1. Sartelli M, Chichom-Mefire A, Labricciosa FM, Hardcastle T, Abu-Zidan FM, et al. (2017) The management of intra-abdominal infections from a global perspective: 2017 WSES guidelines for management of intraabdominal infections. World J Emerg Surg 12(1): 29.

2. Gorter RR, Eker HH, Gorter-Stam MAW, Abis GSA, Acharya A, et al. (2016) Diagnosis and management of acute appendicitis. EAES consensus development conference 2015. Surg Endosc 30(11): 4668-4690.

3. Körner H, Söndenaa K, Söreide JA, Andersen E, Nysted A, et al. (1997) Incidence of acute nonperforated and perforated appendicitis: Agespecific and sex-specific analysis. World J Surg 21(3): 313-317.

4. Bhangu A, Søreide K, Di Saverio S, Assarsson JH, Drake FT (2015) Acute appendicitis: Modern understanding of pathogenesis, diagnosis, and management. Lancet 386(10000): 1278-1287.

5. Andersson RE, Hugander A, Thulin AJG (1992) Diagnostic accuracy and perforation rate in appendicitis: Association with age and sex of the patient and with appendicectomy rate. Eur J Surgery Acta Chir 158(1): 37-41.

6. Rahimian J, Wilson T, Oram V, Holzman RS (2004) Pyogenic liver abscess: Recent trends in etiology and mortality. Clin Infect Dis 39(11): 1654 1659.

7. Huang CJ, Pitt HA, Lipsett PA, Osterman FA, Lillemoe KD, et al. (1996) Pyogenic hepatic abscess: Changing trends over 42 years. Ann Surg 223(5): 600-609.

8. Mohsen AH, Green ST, Read RC, McKendrick MW (2002) Liver abscess in adults: Ten years experience in a UK centre. QJM - Mon J Assoc Physicians 95(12): 797-802.

9. Kaplan GG, Gregson DB, Laupland KB (2004) Population-based study of the epidemiology of and the risk factors for pyogenic liver abscess. Clin Gastroenterol Hepatol 2(11): 1032-1038.

10. Altemeier WA, Culbertson WR, Fullen WD, Shook CD (1973) Intraabdominal abscesses. Am J Surg 125(1): 70-79.
11. Lam YH, Wong SKH, Lee DWH, Lau JYW, Chan ACW, et al. (1999) ERCP and pyogenic liver abscess. Gastrointest Endosc 50(3): 340-344.

12. Meddings L, Myers RP, Hubbard J, Shaheen AA, Laupland KB, et al. (2010) A population-based study of pyogenic liver abscesses in the United States: incidence, mortality, and temporal trends. Am J Gastroenterol 105(1): 117-124.

13. Johannsen EC, Sifri CD, Madoff LC (2000) Pyogenic liver abscesses. Infect Dis Clin North Am 14(3): 547-563 vii.

14. Chen C, Chen PJ, Yang PM, Huang GT, Lai MY, et al. (1997) Clinical and microbiological features of liver abscess after transarterial embolization for hepatocellular carcinoma. Am J Gastroenterol 92(12): 2257-2259.

15. Rubin RH, Swartz MN, Malt R (1974) Hepatic abscess: changes in clinical, bacteriologic and therapeutic aspects. Am J Med 57(4): 601-610.

16. J Tazawa, Y Sakai, S Maekawa, Y Ishida, M Maeda, et al. (1997) Solitary and multiple pyogenic liver abscesses: Characteristics of the patients and efficacy of percutaneous drainage. Amer J Gastroenterol 92: 271274.

17. Cai Y, Xiong X, Lu J, Cheng Y, Yang C, et al. (2015) Percutaneous needle aspiration versus catheter drainage in the management of liver abscess : a systematic review and meta-analysis, pp. 195-201.

18. Malik AA (2010) Pyogenic liver abscess: Changing patterns in approach. World J Gastrointest Surg 2(12): 395-401.

19. Mazuski JE, Tessier JM, May AK, Sawyer RG, Nadler EP, et al. (2017) The surgical infection society revised guidelines on the management of intra-abdominal infection. Surg Infect (Larchmt) 18(1): 1-76

20. Lardière-Deguelte S, Ragot E, Amroun K, Piardi T, Dokmak S, et al. (2015) Hepatic abscess: Diagnosis and management. J Visc Surg 152(4): 231243.

21.Zerem E, Omerovic S, Kunosic S (2014) Sonographically guided percutaneous treatment of liver abscesses in critically Ill patients. J Clin Ultrasound 42(9): 527-533.

22. Rajak CL, Gupta S, Jain S, Chawla Y, Gulati M, et al. (1998) Percutaneous treatment of liver abscesses: Needle aspiration versus catheter drainage. Am J Roentgenol 170(4): 1035-1039.

23. Ch Yu S, Hg Lo R, Kan PS, Metreweli C (1997) Pyogenic liver abscess: Treatment with needle aspiration. Clin Radiol 52(12): 912-916.

24. Singh O, Gupta S, Moses S, Jain DK (2009) Comparative study of catheter drainage and needle aspiration in management of large liver abscesses. Indian J Gastroenterol Off J Indian Soc Gastroenterol 28(3): 88-92.

25. Ahmed S, Chia CLK, Junnarkar SP, Woon W, Shelat VG (2016) Percutaneous drainage for giant pyogenic liver abscess--is it safe and sufficient? Am J Surg 211(1): 95-101.

26. Liao WI, Tsai SH, Yu CY, Huang GS, Lin YY, et al. (2012) Pyogenic liver abscess treated by percutaneous catheter drainage: MDCT measurement for treatment outcome. Eur J Radiol 81(4): 609-615.

27. Tan Y, Edin F, Chung AY, Edin F, Chow PK, et al. (2005) An Appraisal of Surgical and Percutaneous Drainage for Pyogenic Liver Abscesses Larger Than $5 \mathrm{~cm}$ 241(3): 485-490.

28. Liu CH, Gervais DA, Hahn PF, Arellano RS, Uppot RN, et al. (2009) Percutaneous hepatic abscess drainage: do multiple abscesses or multiloculated abscesses preclude drainage or affect outcome? J Vasc Interv Radiol 20(8): 1059-1065.

29. Chen YW, Chen YS, Lee SS, Yen MY, Wann SR, et al. (2002) A pilot study of oral fleroxacin once daily compared with conventional therapy in patients with pyogenic liver abscess. J Microbiol Immunol Infect 35(3): 179-183. 
ISSN: 2574-1241

DOI: 10.26717/BJSTR.2022.41.006577

Matteo Giardini. Biomed J Sci \& Tech Res

(c) (†) This work is licensed under Creative

Submission Link: https://biomedres.us/submit-manuscript.php

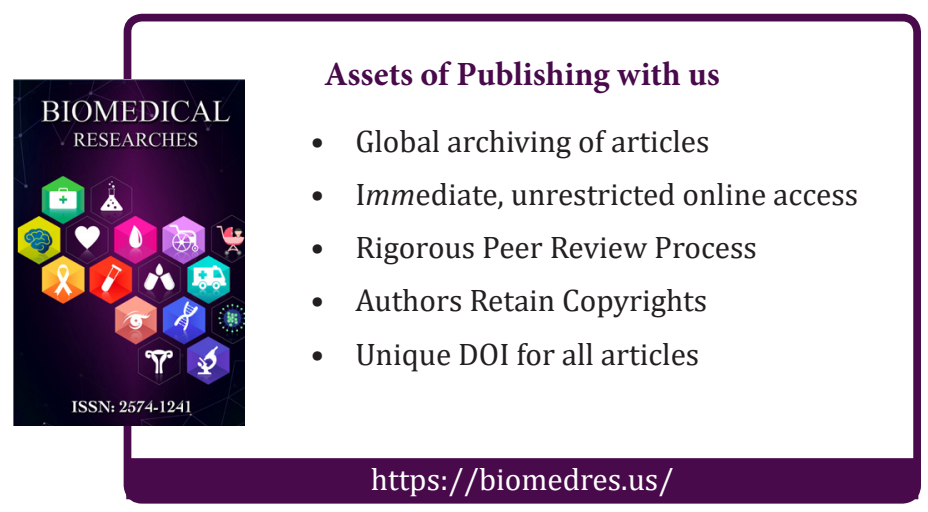

